\title{
Assessment of risk at workplace: A study on radiographers work practices in Vizag Steel
}

\begin{abstract}
The main purpose of this study is to assess the health risks posed by radiographers and to determine whether existing controls at work place are adequate. This small survey conducted in the year 2002. All nine (male) radiographers aged $35-45$ years (median 38 years) and control subjects (24) who were matched for sex, age (within 3-5 years) interviewed using a questionnaire about symptoms experienced during and off work. There were no smokers. The total number of symptoms experienced by the radiographers was greater than controls. Symptoms like headache, and skin irritation were persistent in two radiographers during and off work. Visual observations revealed that, all the radiographers while on work used lead aprons and film badges. Results of personal exposure to ionizing radiation were within the normal limits. Identified hazards in the working environment are (i) exposure to ionizing radiation, (ii) exposure to chemical contaminants. Based on the subjective judgment of radiographers, existing work practices and personal exposure results to ionizing radiation, the estimated risk level was moderate. Risk control action plan developed to bring the risk level to tolerable.
\end{abstract}

Key Words: Risk assessment, subjective symptoms, ionizing radiation, ventilation systems, personal hygiene

\section{INTRODUCTION}

Radiographers and dark room technicians are exposed to a variety of potential chemical hazards and ionizing radiation during their work. The physical and chemical properties of solutions (high acidity or alkalinity) can irritate the skin and mucous membranes. Hydroquinone can cause vitiligo and other chemicals can, in certain cases react together to give off irritating fumes of gases such as sulpherdioxide and ammonia. Previous studies ${ }^{[1,2]}$ revealed a variety of health problems involving respiratory, skin, gastrointestinal, neurological and orthopedic symptoms to exposure to dark room chemicals.

Vizag Steel is an ISO 9001, ISO 14001, and OHSAS 18001 certified public sector organization in India. To fulfill the requirements of Occupational Health and Safety Assessment Series (OHSAS) 18001. ${ }^{[3]}$
(Clause 4.3.1: Planning for hazard identification, risk assessment and risk control), our small study was undertaken. This survey is also aimed to assess symptom complaints among radiographers, personal exposure levels to ionizing radiation and visual assessment of the working environment.

\section{MATERIALS AND METHODS}

All nine radiographers cum dark room technicians (aged 35-45 years, median 38 years, with length of services ranging from 8 to 20 years, median 10 years) were approached and agreed to participate. They worked in two main dark rooms, one of which had in Occupational Health Services and Research Center (OHS and RC) department, and other at Visakha Steel General Hospital (VSGH). All male radiographers (9) were worked full time (48 hours/week). They were manned intermittently in shifts (round the clock) as required. Main dark room (VSGH) processed 70-80 films per day, and at OHS and RC 20-25 films per day. The workload was approximately steady throughout the year. There were no smokers. The controls (24) were selected from volunteers from the administration section, of medical department who were matched for sex, age (within 3-5 years) and smoking habit. The subjects and controls were interviewed separately and privately towards the end of a working day in early September 2002 about a variety of symptoms that might have been experienced during work and off work.

The working environment was assessed through walk-through inspection. Photographs were taken where
P. V. S. Prabhakara Murty,

K. V. Lakshman Rao Occupational Health Services and Research Center (OHS \& RC), Steel Plant, Visakhapatnam - 530 031, India

For correspondence: P. V. S. Prabhakara Murty, (OHS \& RC), Steel Plant, Visakhapatnam - 530 031, India

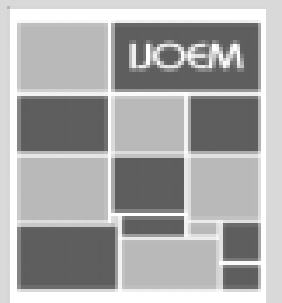


necessary, to document the survey. Film badges worn by radiographers were sent to Bhaba Atomic Research Center (BARC), Mumbai for evaluation of personal exposure to ionizing radiation. Personal monitoring results for ionizing radiation were obtained from the radiologist.

\section{DISCUSSION}

Table 1 summarizes symptoms experienced by the study population. It is evident that the symptoms experienced during work among the radiographers (exposed population) were several times higher compared to controls. The results presented were consistent with the findings reported. ${ }^{[4]}$ We do not have standardized questionnaire to test the results for statistical significance even though the difference of symptoms experienced among subjects and controls were high. Symptoms like headache and skin irritation were persistence in two radiographers during and off work. It is unclear that, the subjective symptoms were associated with the intensity of exposure to various noxious substances in dark room. When the symptoms off work were evaluated, the total subjective symptoms score was approximately same, for both the groups.

Walk-through inspection revealed that poorhouse keeping and unhygienic work places like storage of chemicals, and drinking water facility at the dark room. Chemicals were placed haphazardly and no earmarked place identified for drinking water provision. Personal protective clothing (lead apron) and film badges were worn by the radiographers during work. Radiographers complained about the poor maintenance of ventilation system in dark room at the main hospital (VSGH) and malfunctioning of the existing ventilation system in the dark room at occupational health services center. Visual observation revealed that, radiographers are following an unhygienic work practice to mix the chemicals (developer and fixer) in a container without usage of hand gloves and they

Table 1: Results of symptom questionnaire analysis

\begin{tabular}{lccccc}
\hline Symptom & \multicolumn{2}{c}{ During work } & & \multicolumn{2}{c}{ Off work } \\
\cline { 2 - 3 } \cline { 5 - 6 } & $\begin{array}{c}\text { Radiographers } \\
\text { (n=9) }\end{array}$ & $\begin{array}{c}\text { Controls } \\
(\mathbf{n}=\mathbf{2 4 )}\end{array}$ & & $\begin{array}{c}\text { Radiographers } \\
\text { (n=9) }\end{array}$ & $\begin{array}{c}\text { Controls } \\
\text { (n=24) }\end{array}$ \\
\hline Headache & $7(77)$ & $6(24)$ & & $2(22)$ & $3(12)$ \\
Skin irritation & $5(55)$ & $1(4)$ & & $2(22)$ & $0(0)$ \\
Nasal irritation & $3(33)$ & $1(4)$ & & $1(11)$ & $0(0)$ \\
Mouth & $2(22)$ & $1(4)$ & & $0(0)$ & $0(0)$ \\
Cough & $5(55)$ & $2(8)$ & & $1(11)$ & $2(8)$ \\
Nausea & $2(22)$ & $0(0)$ & & $0(0)$ & $0(0)$ \\
Watery eyes & $2(22)$ & $2(8)$ & & $0(0)$ & $0(0)$ \\
Blurred Vision & $2(22)$ & $0(0)$ & & $0(0)$ & $0(0)$ \\
Wheeze & $0(0)$ & $0(0)$ & & $0(0)$ & $0(0)$ \\
Dizziness & $2(22)$ & $1(4)$ & & $1(11)$ & $0(0)$ \\
Unusual Tiredness & $4(44)$ & $1(4)$ & & $0(0)$ & $0(0)$ \\
Tinnitus & $1(11)$ & $0(0)$ & & $0(0)$ & $0(0)$ \\
Total score & 35 & 15 & 7 & 5 \\
\hline
\end{tabular}

All parenthesis are in percentage stir the solution with a one-meter long stick. Poor work practices of radiographers (without usage of hand gloves) in dark room while developing and fixing of X-ray film may lead to the chemical spills on the skin. The predominance of skin irritation symptoms may have been due to the fact of poor work practices. There were no symptoms of wheezing, which might be expected as a result of inhaling vapors and gases. One subject in the exposed group complained about loss of hair during his employment period (11 years). We do not have retrospective data on personal exposure to ionizing radiation and chemical exposures to evaluate the complaint of hair loss. There are hereditary conditions, which include hair loss as a prominent part of the condition. The questionnaire did not specifically address the problem of hair loss in the family history.

Personal monitoring assessments for ionizing radiation showed that the dose level varied from 0.05 to 2.60 milliSievert (mSv) for the period from January to September 2002. This was within normal limits (annual effective dose limit is 30 $\mathrm{mSv}$.). Based on the likelihood that a hazard may occur (unlikely) and the consequence of hazardous event (harmful) the risk level estimated was moderate. Safety related hazards like electric shock, slips and falls have also been taken into consideration in the estimation of risk. A simple risk level estimation model was presented in the literature. ${ }^{[5]}$

Risk control action plan developed to bring the risk level to tolerable.

- Monitoring the usage of personal protective equipments, personal exposure levels to ionizing radiation by radiologist, occupational health physician, and industrial hygienist.

- Periodical maintenance of ventilation systems in dark rooms at VSGH and OHS\&RC.

- Initiation for work place monitoring (area as well as personal) for chemical contaminants by industrial hygienist.

- Periodical health checkups to radiographers.

- Education about workplace hygiene and personal hygiene.

In addition to the risk control action plan, we felt the need for standardization of present questionnaire and assessment of subjective symptoms experienced by radiographers during and off work to know about their consistency and to test for statistical significance.

\section{CONCLUSION}

This small study has shown that the need for standardization of the present questionnaire. Further studies are required to see if symptom complaints are consistent and the results are statistically significant. Other confounding factors like non-work related sources, personal hygiene, drinking water supplies represent a challenge in study design and interpre- 
tation of results. Personal monitoring of chemical exposure has to be conducted to correlate with symptom complaints. Internal and external auditing of the present system for OHSAS 18001 provides a good insight for continual improvement in minimizing the risk level to the radiographers working in a hospital of Vizag Steel.

\section{ACKNOWLEDGEMENTS}

We would like to thank Dr. B. B. Mohapatra, Deputy General Manager (Medical and Health Services) I/C, for his advice and encouragement. We would like to thank Dr. S. S. Patnaik, Radiologist and the staff of radiology department for their cooperation during our study period.

\section{REFERENCES}

1. Gordon M. The effects on health of inhaling toxic chemical fumes given off during processing of X-ray films. Shadows 1984;27:28-33.

2. Kipen HM, Lerman Y. Respiratory abnormalities among photographic developers: A report of three cases. Am J Ind Med 1986;9:341-7.

3. OHSAS 18001:1999. Occupational Health and Safety Management Systems - specification, and BSI reference: Amendment 14223.

4. Ide CW. Developments in the darkroom: A cross-sectional study of sickness absence, work-related symptoms and environmental monitoring of darkroom technicians in a hospital in Glasgow. Occp Med 1993;43:27-31.

5. British Standard 8800:1996. Guide to Occupational health and safety management systems. 